\title{
Lymphangiography and Lymphatic Interventions
}

Ajit Yadav ${ }^{1}$ Yajush Jain ${ }^{1} \quad$ Amey Narkhede ${ }^{1} \quad$ Mahendra KM $^{1} \quad$ Arun Gupta $^{1}$
Address for correspondence Ajit Yadav, DNB, EBIR, Department of Interventional Radiology, Sir Ganga Ram Hospital, Sir Ganga Ram Hospital, New Delhi, 110060, India (e-mail: yadavajitdr@gmail.com).
Abstract
Keywords
- lymphangiography
- embolization
- chylous leak
- lymphatic embolization
- lymphatic system

Compared with the traditional pedal lymphangiography, intranodal lymphangiography and MR lymphangiography have made imaging of the lymphatic system less challenging. Improvements in imaging and availability of newer catheters have allowed embolization of lymphatic system much more feasible that previously envisioned. In this article, we briefly review the anatomy, imaging, and current and future of lymphatic interventions.

\section{Introduction}

Hippocrates gave one of the first descriptions about the lymphatic system in $400 \mathrm{BC}$ as a "vessel containing white blood." Carl Friedrich Wilhelm Ludwig (1816-1895) suggested that lymph was a blood filtrate derived from the capillary wall by intracapillary pressure. Later, Ernest Henry Starling (18661927) provided the Starling equation, describing forces that govern the fluid motion across capillary, resulting in the formation of lymph. ${ }^{1}$ Constantin Stan Cope (1927-2016) was the first to describe the role of interventional radiology in various pathologies of lymphatic channels.

\section{Anatomy and Physiology of Lymphatic System}

At the capillary level, there is an outward seepage of fluid through endothelial openings, resulting in the formation of protein-rich interstitial fluid. This interstitial fluid, when it enters the small lymphatic channels, is then termed as lymph. ${ }^{2}$ The lymphatic system acts as a unidirectional flow channel, which helps the lymph to return into the circulatory system, thereby controlling the volume of extracellular fluid and hence achieving hemostasis (-Fig. 1). Apart from its role in the circulatory system, the lymphatic system also plays a role in the conduit of immune cells and helps to facilitate the immune response, thereby making it an integral part of the immune system.

The lymphatic system is a complex system with highly variable anatomy. The lymphatic vasculature is divided into two components, the initial lymphatic network (blind-ended, non-contractile, lack valves) and the collecting lymphatic vessel. ${ }^{2}$ The lymphatic system is categorized as the peripheral system and central conducting system. The imaging technique can be selected, depending on whether peripheral system (like lymphoscintigraphy and pedal lymphangiography) or central conducting system (like intranodal lymphangiography) needs to be examined.

Cisterna chyli is a saccular dilatation of lymphatic channels located in the retrocrural space adjacent to the abdominal aorta at the level of L1-L2 vertebrae.,4 Two lumbar and intestinal lymphatic trunks join at cisterna chyli and then continue in the cephalic direction as the thoracic duct. There is a high-degree of variation regarding the appearance of cisterna chyli, which attributes to the complex anastomosis of lumbar lymphatics, resulting in plexus rather than a single duct. Besides, there may be the presence of multiple sacculations in some convergent lymphatics; therefore, one should consider the term cisterna chyli of only topographic value.
DOI https://doi.org/ 10.1055/s-0041-1726165 ISSN 2457-0214.
(C2021. Indian Society of Vascular and Interventional Radiology. This is an open access article published by Thieme under the terms of the Creative Commons Attribution-NonDerivative-NonCommercial-License, permitting copying and reproduction so long as the original work is given appropriate credit. Contents may not be used for commercial purposes, or adapted, remixed, transformed or built upon. (https://creativecommons.org/licenses/by-nc-nd/4.0/).

Thieme Medical and Scientific Publishers Pvt. Ltd. A-12, 2nd Floor, Sector 2, Noida-201301 UP, India 
Rosenberger et al and Williams et al in different studies demonstrated that cisterna chyli is challenging to visualize and can be seen only in $52 \%$ of lymphangiography studies and in $20 \%$ autopsy studies, respectively. ${ }^{5,6}$ The most common shapes are an inverted letter $\mathrm{Y}$ or $\mathrm{V}$, a string of pearls, and a comma-like configuration $^{4}$ ( - Fig. 2 ).

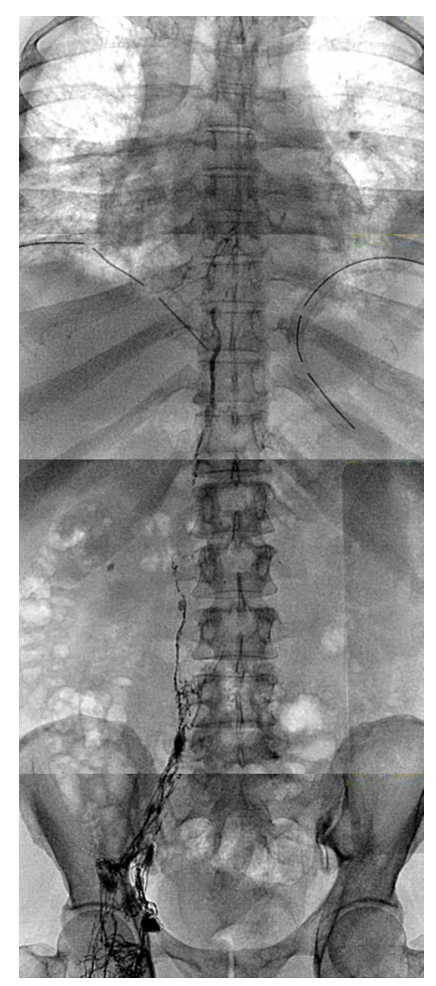

Fig. 1 Normal lymphatic system on intranodal lymphangiography.

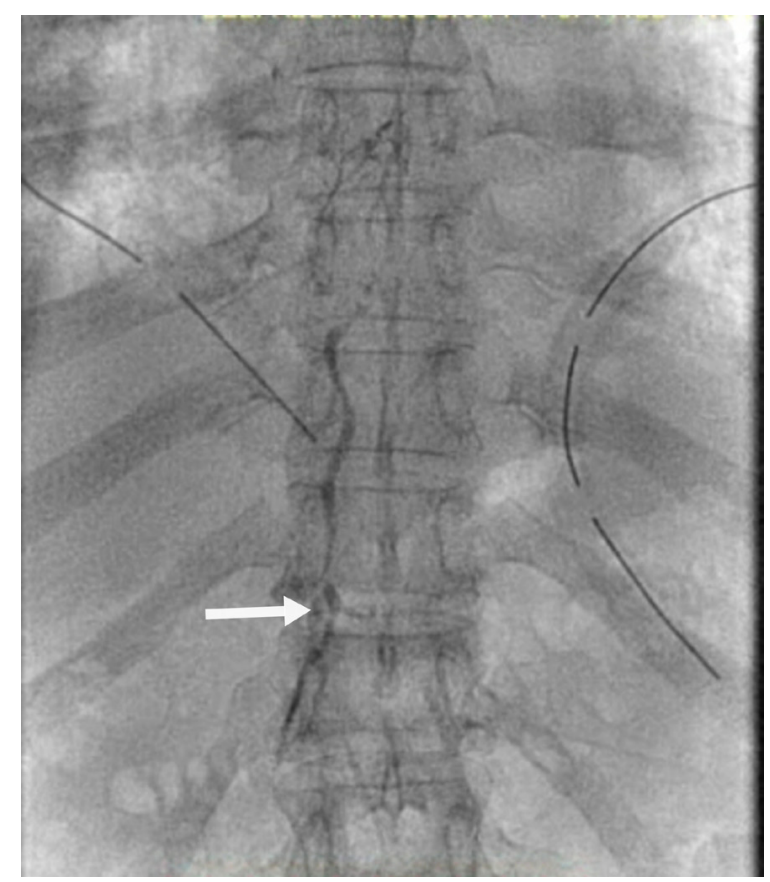

Fig. 2 White arrow shows cisterna chyli in inverted $Y$ configuration

\section{Thoracic Duct}

During embryonic development, there are two thoracic ducts with transverse anastomosis at multiple levels. The lower two-third of adult thoracic duct develops from the embryonic right thoracic duct, and the upper one-third develops from the embryonic left thoracic duct. This is the most common anatomical variant of the thoracic duct as described by Okuda et al. ${ }^{7}$

The thoracic duct originates at the upper abdomen just cephalad to cisterna chyli, enters the thoracic cavity through aortic hiatus, and finally drains into great veins of the left neck, making it the longest lymphatic duct in the body, which measures $45 \mathrm{~cm}$ in length (-Fig. 3). This anatomic configuration has been seen in only 40 to $60 \%$ of the population. ${ }^{3,8}$

There are multiple variations to this standard thoracic duct configuration, and various authors have tried to describe these variations. Kausel et al have described the thoracic duct into five types, based on morphological characteristics. The importance of $\mathrm{V}$ type, a plexiform variant, rests in the fact that this anatomic variation demands a proximal thoracic duct embolization because of difficulty in advancing the wire and catheter distally. ${ }^{9}$

The entry of the thoracic duct into the venous system can also demonstrate variations in the form of entry location and number of entry ducts. Phang et al reported that the most common pattern of termination is into the jugular vein (46\%), followed by within $2 \mathrm{~cm}$ of jugulovenous angle (32\%), subclavian vein (18\%), and other veins (4\%). These $4 \%$ of cases with other termination sites include the external jugular vein, vertebral vein, transverse cervical vein, brachiocephalic vein, and suprascapular vein..$^{10}$ There can be a single-entry point, which is a commoner pattern and was seen in approximately $3 / 4$ three-fourth of the study population. ${ }^{10}$

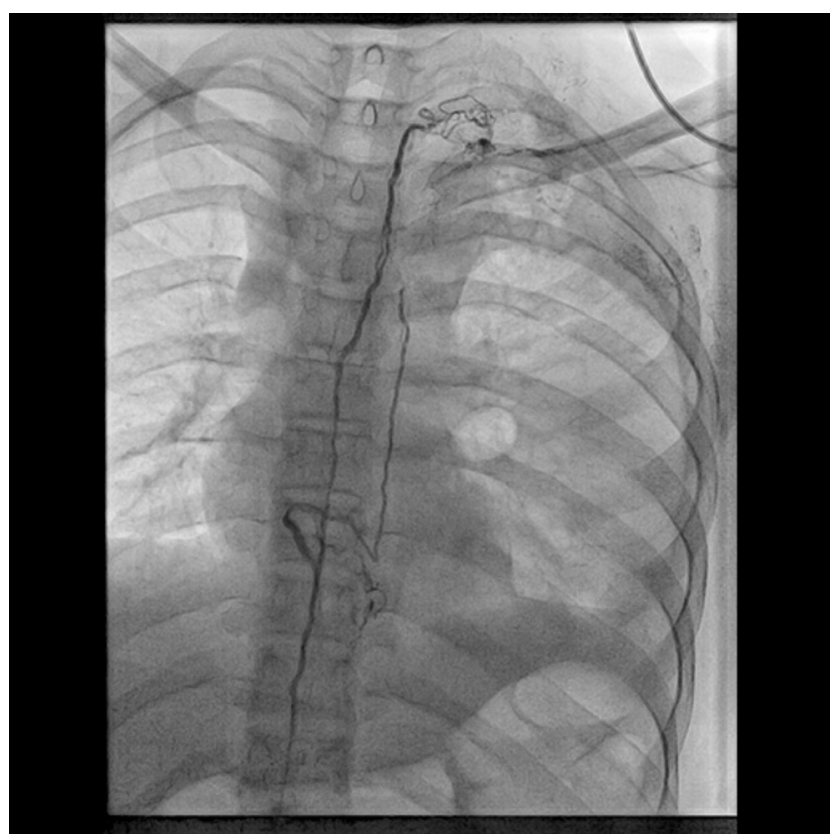

Fig. 3 There is evidence of two contrast opacified lymphatic ducts running parallel to each other in thoracic cavity and finally draining into the left-sided venous system. 


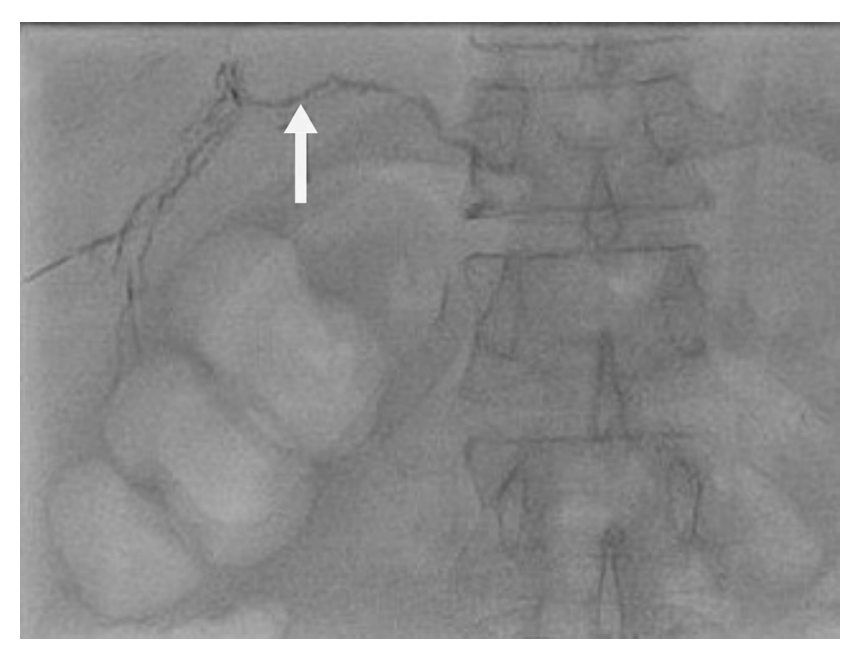

Fig. 4 White arrow shows the incidental cannulation and opacification liver lymphatics by contrast agent while performing percutaneous transhepatic biliary drainage.

\section{Hepatic Lymphatics}

The liver produces around 25 to $50 \%$ of total lymph flowing through the thoracic duct. Unlike the vascular and biliary system, there is no segmental delineation of lymphatic drainage. ${ }^{11}$ The hepatic lymphatic system is divided broadly into deep and superficial networks. Lymphatic channels form the superficial system mainly consists of lymphatic drainage from the inferior and convex surface of the liver. The deep system follows the ramification of the portal and hepatic veins and is responsible for $80 \%$ hepatic drainage. ${ }^{12}$

Cross-sectional imaging does not help identify the normal hepatic lymphatics; however, they may be incidentally seen during percutaneous transhepatic biliary drainage (PTBD) or direct portography (-Fig. 4). They appear as tortuous, beaded, multichannel network extending medially and inferiorly, often misinterpreted as abnormal intrahepatic biliary ducts.

\section{Intestinal Lymphatics}

There are three layers of lymphatics in the intestine: the lacteals in the villi, submucosal lymphatic network, and lymphatic system in the smooth muscle layer. ${ }^{13}$ Apart from fluid homeostasis and immune surveillance, other significant roles of intestinal lymphatics include the transportation of dietary fat and fat-soluble vitamins. The lymph from the intestinal lymphatic along with lumbar lymphatics is finally drained into cisterna chyli.

\section{Imaging of the Lymphatic system}

Lymphangiography is an outpatient procedure that provides either structural, functional, or dual information regarding the lymphatic system. It is primarily indicated in patients with chylous leaks; however, it also helps in identifying site of lymphatic obstruction, abnormal lympho-lymphatic, or lymphovenous connections. Contraindications to lymphangiography should always be assessed before the procedure. These include pulmonary insufficiency and a right to left cardiac shunt.
There are currently three methods of lymphangiography: 1. Conventional lymphangiography, 2. Magnetic Resonance Lymphangiography, and 3. Lymphoscintigraphy.

\section{Conventional Lymphangiography}

This method remains the gold standard for imaging of lymphatics.

\section{Contrast Material}

At many institutes, lipiodol is the preferred choice of contrast agent as it is oil-based; there is a minimal leak of contrast out of vessel lumen due to restricted outward diffusion. Second, the lipiodol may persist in nodes for months and sometimes years, allowing one to evaluate the effect of treatment and progression of the disease. Finally, whenever there is extravasation of lipiodol from the leak site, it initiates an inflammatory and granulomatous reaction in the surrounding tissue, ultimately resulting in occlusion of leak site and thereby acting as a therapeutic agent in addition to its diagnostic properties.

A dose of $1 \mathrm{~mL} / 10 \mathrm{~kg}$ per limb has to be administered with an upper limit of $10 \mathrm{~mL}$ for a single leg and $14 \mathrm{~mL}$ for both limbs. ${ }^{14}$ The rate of contrast administration should never exceed 4 to $10 \mathrm{~mL} /$ hour (depending upon the size of lymphatics), as a rapid injection rate can lead to the rupture of lymphatics $^{14}$ (-Fig. 5). A higher contrast dose of more than $20 \mathrm{~mL}$ should be cautiously administered in cases of lymphovenous communication.

\section{Technique}

Depending upon the site of contrast injection, lymphangiography has been categorized as intranodal lymphangiography or pedal lymphangiography (- Table $\mathbf{1}$ ).

The most important complications are pulmonary oil embolism and pulmonary infarction. Other complications are hypersensitivity reaction to the contrast agent, intra-alveolar hemorrhage, hypothyroidism, and systemic arterial embolism to the brain or kidney.

\section{Magnetic Resonance Lymphangiography}

MR imaging has primarily been based on heavily T2-weighted sequences, which helps in accentuating the signals from static or slow-moving fluid-filled structures. ${ }^{15}$ Noncontrast Magnetic Resonance Lymphangiography (NCMRL) and dynamic contrast material-enhanced magnetic resonance (DCE MR) lymphangiography are the available methods for magnetic resonance lymphangiography .

NCMRL is a newly described method for imaging of the lymphatic system and is similar to MRCP and MR urography; however, there is a lack of established validation for its use. It only provides structural information of abnormally dilated lymphatic vessels. ${ }^{16}$ Apart from the advantage of being noninvasive, it can also be helpful in patients of pediatric age group, and in patients with a contraindication to the use of the contrast material.

DCEMR is a contrast-enhanced MR study. A dose of $0.1 \mathrm{mmol} / \mathrm{kg}$ body weight. Gadolinium-based contrast 


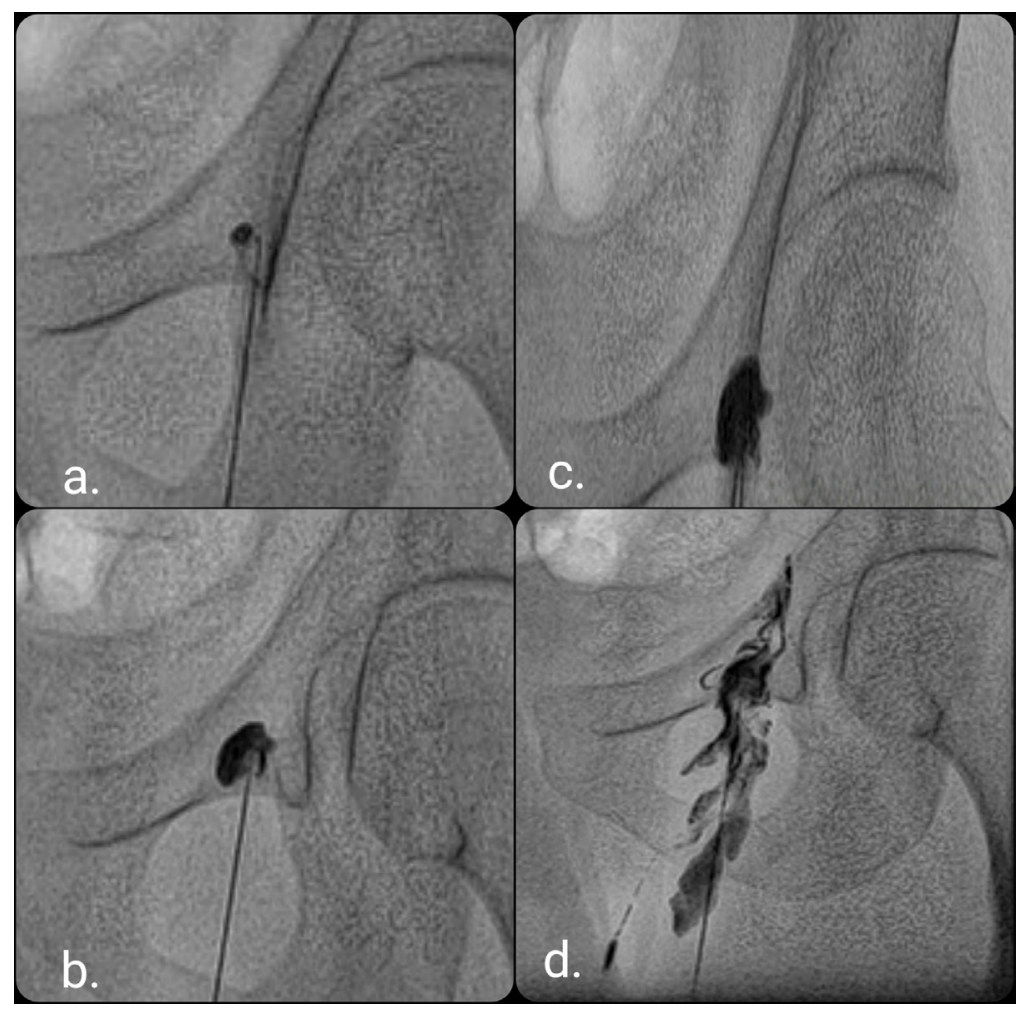

Fig. 5 Figure (a-d) shows a gradual increase in opacification of lymph node by contrast with rupture and spillage of contrast in (d) due to a greater rate of contrast administration.

Table 1 Differences between intranodal and pedal lymphangiography

\begin{tabular}{|l|l|l|}
\hline & $\begin{array}{l}\text { Intranodal } \\
\text { lymphangiography }\end{array}$ & $\begin{array}{l}\text { Pedal } \\
\text { lymphangiography }\end{array}$ \\
\hline $\begin{array}{l}\text { Location } \\
\text { of contrast } \\
\text { injection }\end{array}$ & Inguinal lymph nodes & Feet/hand \\
\hline Method & $\begin{array}{l}\text { A 22-25G needle can be } \\
\text { placed at the junction of } \\
\text { cortex and hilum under } \\
\text { USG guidance (-Fig. 6) }\end{array}$ & $\begin{array}{l}\text { A vertical incision } \\
\text { lateral to 1st metatarsal } \\
\text { and afterward a fine } \\
\text { catheter/needle can be } \\
\text { inserted into the lym- } \\
\text { phatic vessel. (-Fig. 7) }\end{array}$ \\
\hline $\begin{array}{l}\text { Evaluation } \\
\text { of CCL }\end{array}$ & Useful & Not useful \\
\hline $\begin{array}{l}\text { Evaluation } \\
\text { of } \\
\text { peripheral } \\
\text { lymphatics }\end{array}$ & Not useful & Useful \\
\hline
\end{tabular}

Abbreviation: CCL, central conducting lymphatics. material is mixed with saline in a ratio of $1: 1$ or $1: 2$, depending on the age of the patient. ${ }^{17}$ The total volume is distributed equally in two parts and is then administered through each limb. Similar to conventional lymphangiography, the contrast material can be administered through either the intranodal or pedal pathway. In addition to T2-weighted images, contrast sequences are also acquired, thereby providing both structural and functional information of the lymphatic system. In contrast to NCMRL, in DCEMR, normal and hypoplastic lymphatics are also visualized.

MR lymphangiography is less time consuming and safer in terms of radiation; however, if any pathology is detected, therapeutic embolization cannot be performed as opposed to conventional lymphangiography.

\section{Lymphoscintigraphy}

This method is mostly reserved for imaging of extremity lymphatics. A dose of 74 to $296 \mathrm{MBq}$ of $99 \mathrm{mTc}$ sulfur colloid suspended in $0.10 \mathrm{~mL}$ of saline is used in a fashion similar to pedal lymphangiography. ${ }^{18} \mathrm{~A}$ high-resolution collimator is used, so that images of at least 300,000 counts are acquired.

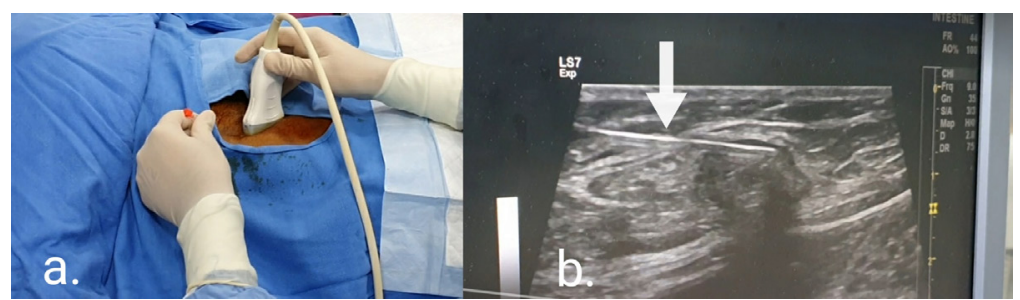

Fig. 6 (a-b) Ultrasound-guided puncture of inguinal lymph node using a 25G spinal needle (white arrow) 


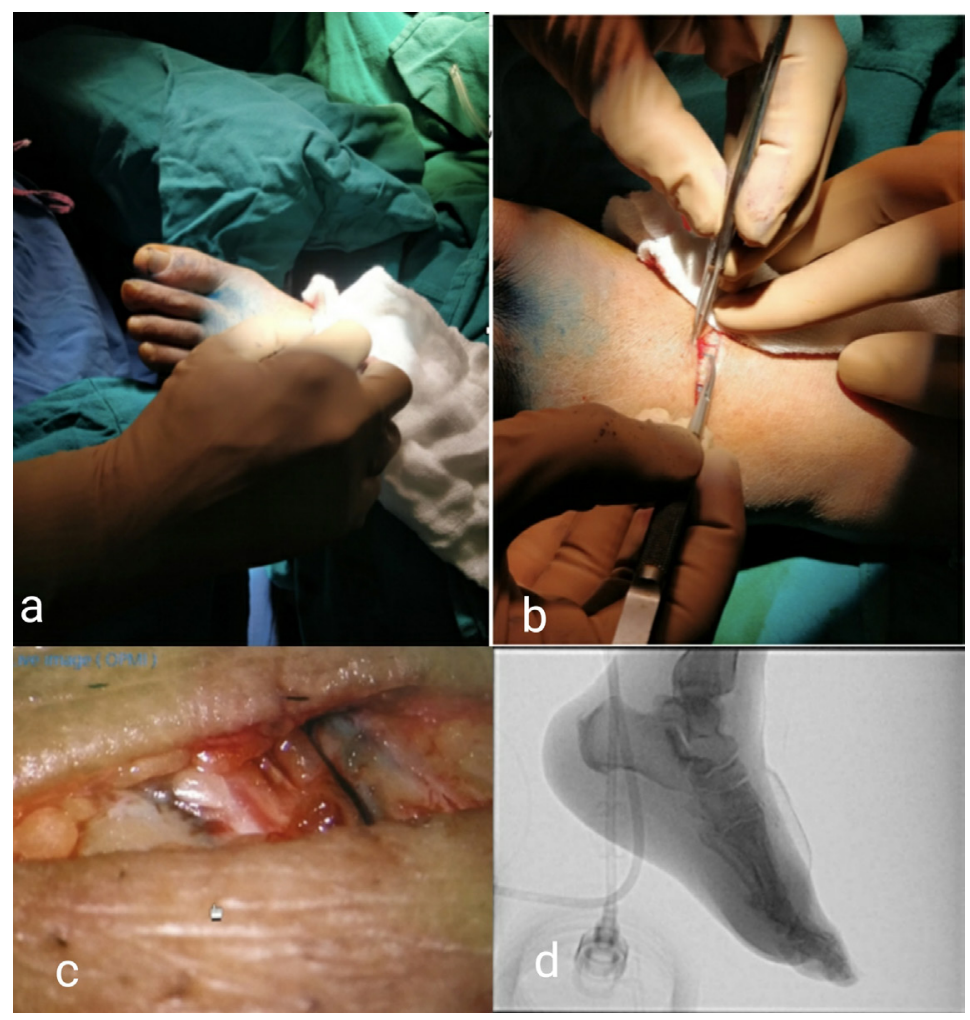

Fig. 7 Pedal lymphangiography. (a) Infusion of blue dye in foot web spaces. (b) Small horizontal incision $2 \mathrm{~cm}$ above web space on dorsal part of foot. (c) Fine dissection showed dye in lymphatic vessel. (d) Selective cannulation of small lymphatic vessel with 30G needle and lipiodol injection show opacification of ducts. (Courtesy: Dr. Abhishek Bansal, Delhi).

Spot and whole-body images are obtained for up to 3 to 4 hours. The study can be tailored according to the need as per individual findings.

There are, however, a few limitations to this method, which include poor spatial resolution, exposure to radioactive material, and added cost when combined with CT. There is also a need for special protective equipment and waste handling for the radioactive compound used in this method. ${ }^{19}$

\section{Pathology of Lymphatic System}

Approximately 2 to $4 \mathrm{~L}$ of chyle flows through the thoracic duct every day, varying according to the dietary habits of a person. Chyle is a fluid consisting of lymph and emulsified fat (mostly in the form of triglycerides) from intestinal lacteals.

There are several known causes for chylous leaks (like chylous ascites, chylothorax, and chyluria), which are broadly categorized into nontraumatic and traumatic causes (iatrogenic causes, blunt, or penetrating injury). Abdominal surgeries like retroperitoneal lymphadenectomy, pancreaticoduodenectomy, and vagotomy are few iatrogenic causes for chylous ascites. Similarly, thoracic surgeries and esophagectomy (in cases of esophageal carcinoma) are important iatrogenic causes of chylothorax with an incidence rate of $0.42 \%$ and $3.9 \%$, respectively. ${ }^{20-22}$

Fluid can be suspected of chylous nature if it is whitish or milky in appearance ( - Fig. 8). Further investigations by measurement of chylomicron level ( $>4 \%$ ), triglyceride level (> $110 \mathrm{mg} / \mathrm{dl}$ ), and lymphocytes (> 50\%) in the fluid help

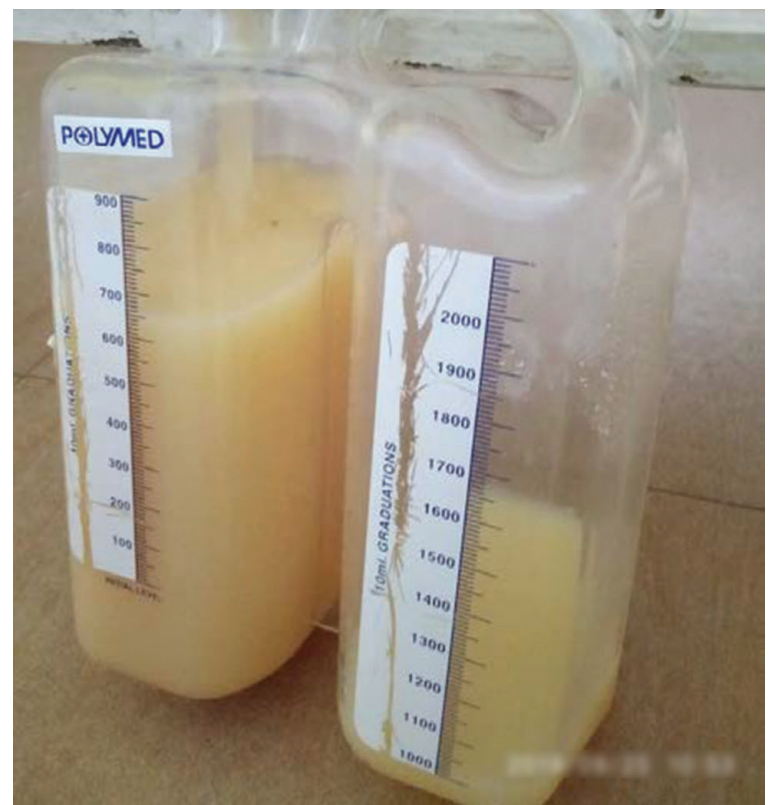

Fig. 8 Chylous leak with high-output noted as milkish fluid with high-triglyceride level.

establish the nature of fluid. ${ }^{23,24}$ Persistent chyle leak can result in malnutrition, electrolyte imbalance, and immune compromise. Chylous leaks are defined as low-output $(<1000 \mathrm{~mL} /$ day), which are traditionally treated with medical management or high-output ( $>1000 \mathrm{~mL} /$ day) requiring surgical ligation or embolization therapy. ${ }^{25}$ 
Lymphoceles and lymphatic fistula are generally caused by blunt trauma or postsurgery which may remain confined, forming a lymphocele or may exit through surgical wound.

\section{Management}

Patients with low-output leaks are managed conservatively which includes adequate drainage, bed rest, and modification to fat-free diet..$^{22}$ Octreotide has also been indicated in the management of chylous leaks and acts by decreasing the rate of chyle production. ${ }^{21,22}$ These patients may need surgical or embolization therapy if there is no decrease in output or if there is the persistence of leak for more than two weeks (-Fig. 9).

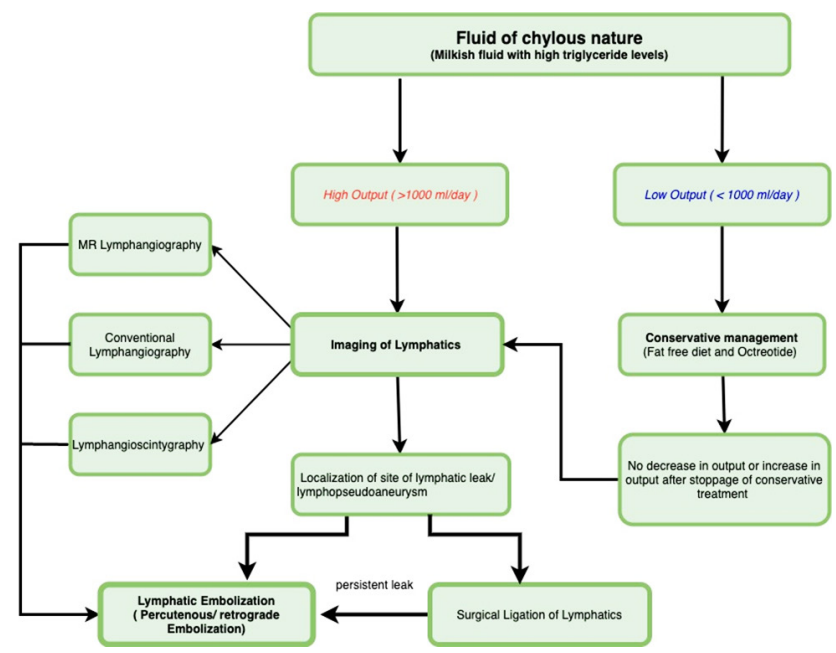

Fig. 9 Management plan for patients with chylous leak.
The patients with high-output leaks are generally offered surgical therapy in the form of thoracic duct ligation. Surgical ligation of the thoracic duct has morbidity and mortality rates up to $38 \%$ and $2.1 \%$, respectively. ${ }^{21}$

Percutaneous thoracic duct embolization has been offered as a minimally invasive alternative to surgical ligation of the thoracic duct in patients with high-output chylous leaks. Once the leak site is confirmed on intranodal lymphangiography, embolization can be performed in the same setting.

Various approaches can be used to cannulate the lymphatic system, as described below. Once successful cannulation has been achieved, a guidewire is inserted into the lymphatic channels. Thereafter, a microcatheter (1.7-2.7 Fr) is advanced over the 0.014-inch guidewire up to the site of disruption. Embolization can be performed by metallic coils or n-Butyl cyanoacrylate (NBCA) at the location of the leak or in the central thoracic duct.

\section{Transabdominal/Translumbar Direct Puncture}

This is the most commonly practiced approach when intranodal lymphangiography demonstrates normal thoracic duct anatomy. The thoracic duct or cisterna chyli is punctured using a 21G Chiba needle under fluoroscopic guidance in the right anterior oblique view with a caudal angulation to avoid penetration of the aorta. ${ }^{26}$ The Chiba needle is withdrawn, and a guidewire is inserted into the TD; then, a microcatheter (1.7-2.7 French) is advanced over the wire to the site of the leak, and embolization is performed ( - Fig. 10). If cannulation of the cisterna chyli is not feasible, adequate fenestration of cisterna chyli can be therapeutic.

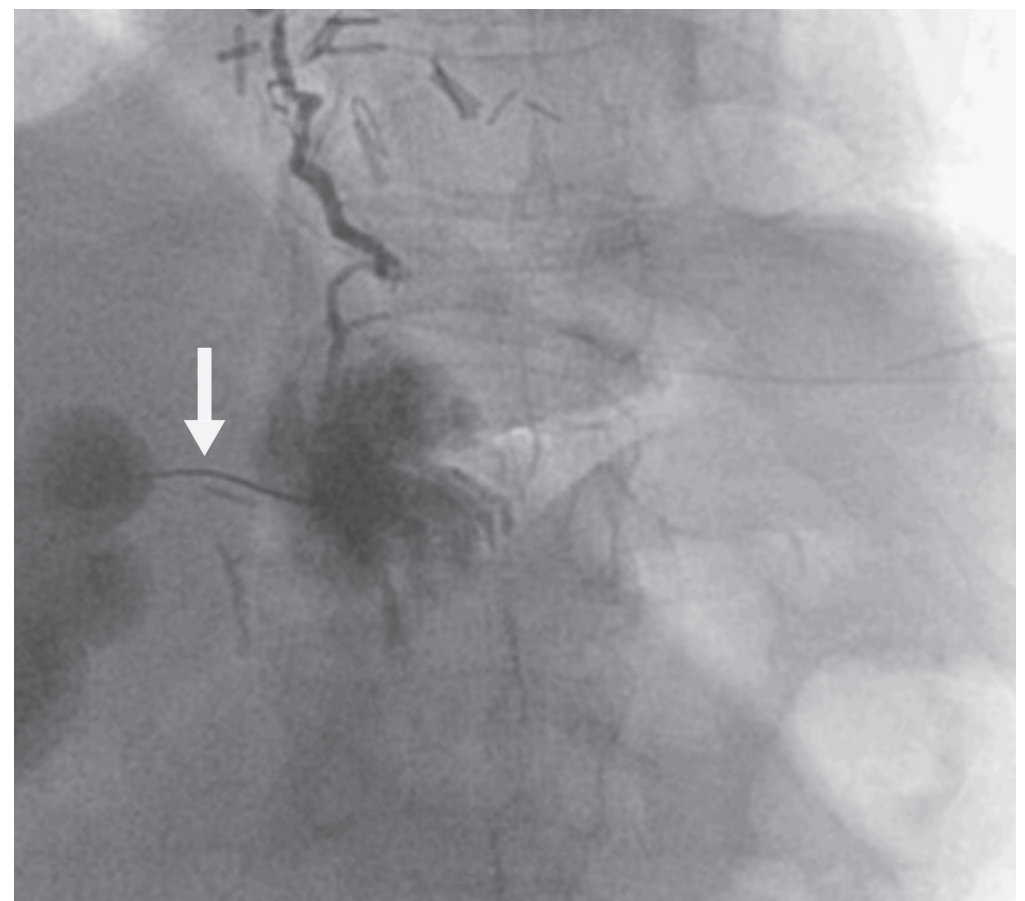

Fig. 10 White arrow marks the 22G Chiba needle used for direct transabdominal puncture of previously opacified lymphatic channel (through intranodal lymphangiography). 


\section{Retrograde Venous Approach}

This approach is used in patients with anatomic variations such as a left-sided thoracic duct or a plexiform variety. As the name suggests, this approach involves gaining access to the thoracic duct via the basilic or cephalic vein through the ostial valve of the thoracic duct ${ }^{26}$ ( - Fig. 11). The entry point of the thoracic duct into a systemic vein can be visualized using the various lymphangiographic techniques described above.

With the reference to imaging information (lymphatic system), a peripheral left venous access is secured and a 5F catheter (most commonly Simonds Type catheter) is advanced up to the ostial valve at the entry site of the thoracic duct into the venous channel. Afterward, a microcatheter and a 0.014-inch guidewire can be coaxially introduced into the thoracic duct.

\section{Transhepatic Approach}

Hepatic lymphorrhea is a rare complication postsurgery, and limited literature is available for its exact management. As the hepatic lymphatics are thin and tortuous channels, they limit the introduction and navigation via a guidewire and catheter ${ }^{26}$ They are directly embolized using a Chiba needle and liquid-embolizing material.

\section{Direct Puncture of the Leakage Site}

This technique is used when none of the above-described methods are feasible. CT guidance can be used, and sclerosing agents can be injected into lymphatics adjacent to the leak site. ${ }^{26}$

\section{Closest Upstream Lymph Node Embolization}

The lymph node from which efferent lymphatic vessels are extravasated on lymphangiography is labeled as the closest upstream lymph node, as described by Hur et al. ${ }^{27}$ This node can be visualized on fluoroscopy or $\mathrm{CT}$, and after injecting a test dose of lipiodol to confirm the leak, embolization can be performed (-Fig. 12). A $26 \mathrm{G}$ needle or lesser should be used to prevent the disruption of lymph node parenchyma. A low-percentage of glue (5\%) can be directly injected through the needle, and flow-directed glue embolization can be documented on fluoroscopy.

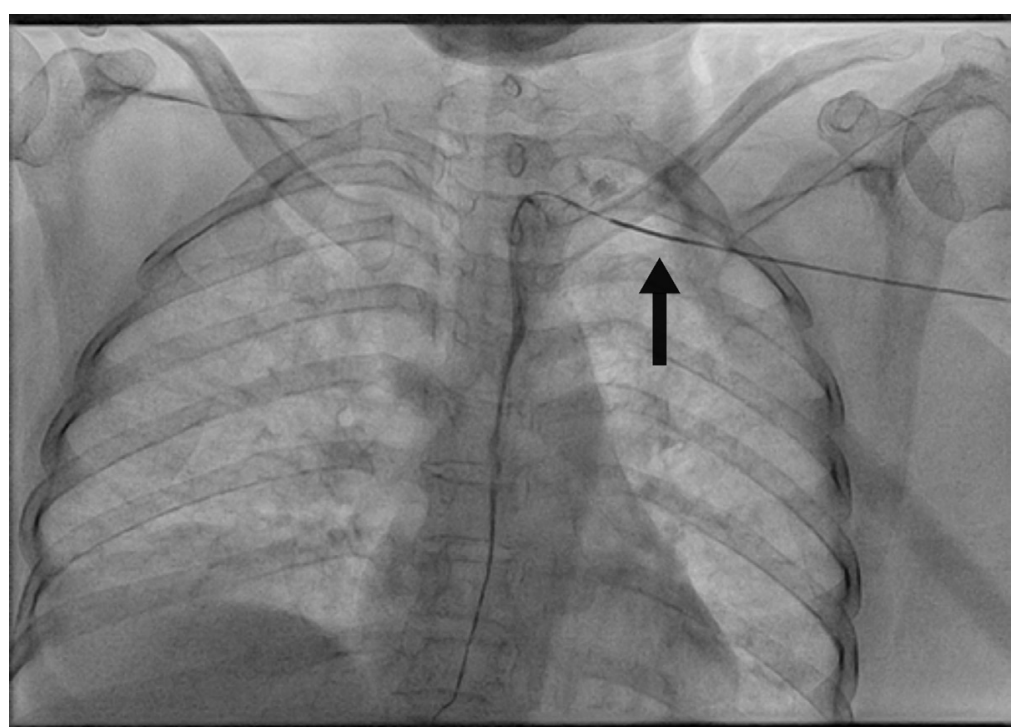

Fig. 11 Black arrow demarcates the used of wire and microcatheter system to enter the previously opacified lymphatic channels through the termination site of lymphatic system.

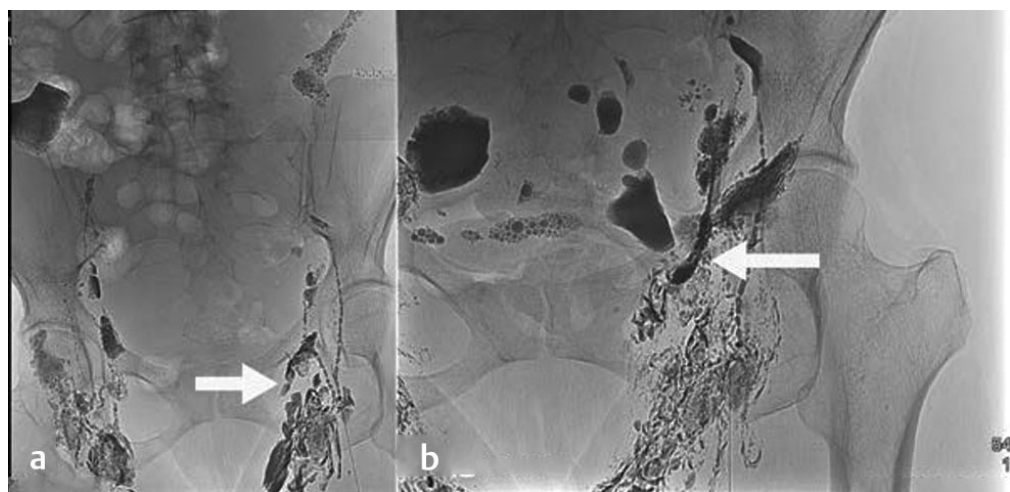

Fig. 12 (a) White arrow marks the site of leak. (b) White arrow shows embolization of closest upstream lymph node using glue as embolizing material. (Courtesy: Dr. Rahul KR, Kerala). 


\section{Embolization Material}

Glue (n-Butyl cyanoacrylate [NBCA]) is the preferred choice of embolizing agent for lymphatic leaks. Glue is generally mixed with lipiodol in a ratio of $1: 2$ to $1: 4$. As a result of almost stagnant flow, ionic exposure is low in the thoracic duct. Therefore, one should make a note of using a maximum amount of $0.3 \mathrm{~mL} 5 \%$ dextrose in water (D5W) for the flushing of the catheter. A higher amount of D5W will delay the polymerization of the NBCA, and the recanalization of glue cast can occur. A coil can also be deployed before glue injection, which can act as a scaffold for glue cast (-Figs. 13-15).

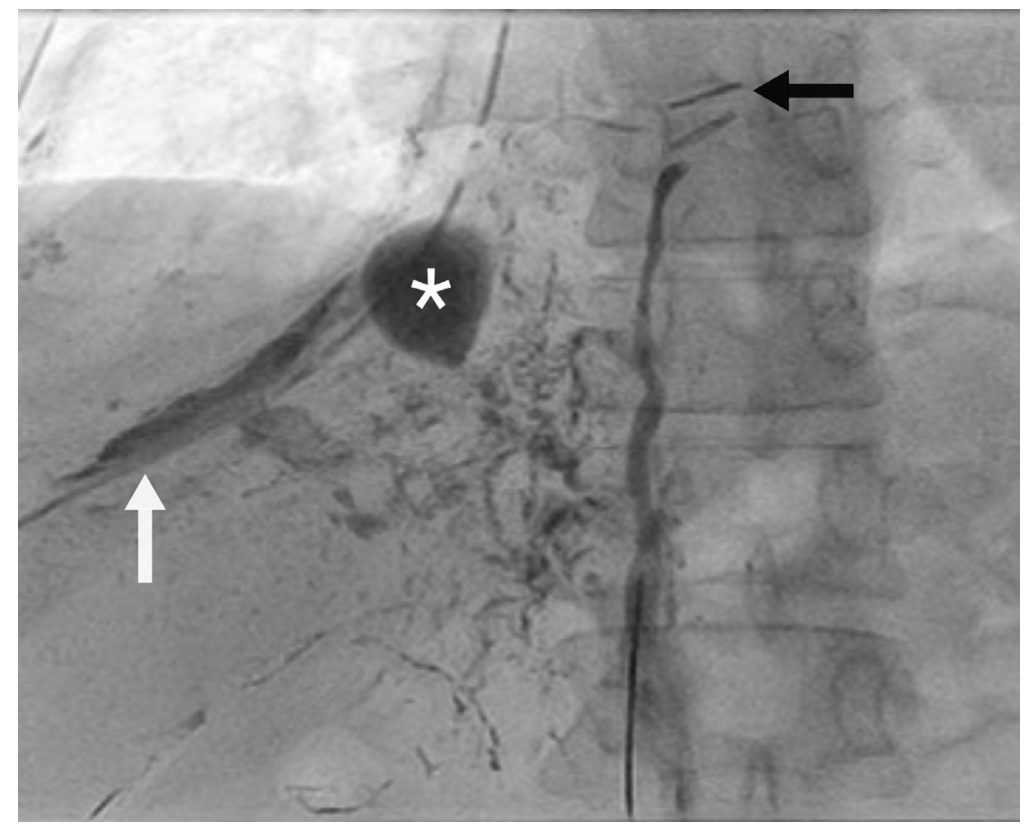

Fig. 13 Figure represents a case of persistent chyle leak postthoracic duct ligation. Black arrow demarcates surgical clips from previous attempt to stop chyle leak through thoracic duct ligation. White arrow marks the drain catheter placed for drainage of chylous effusion, asterisk demarcates lymphopseudoaneurysm, leading to persistent chylous effusion.

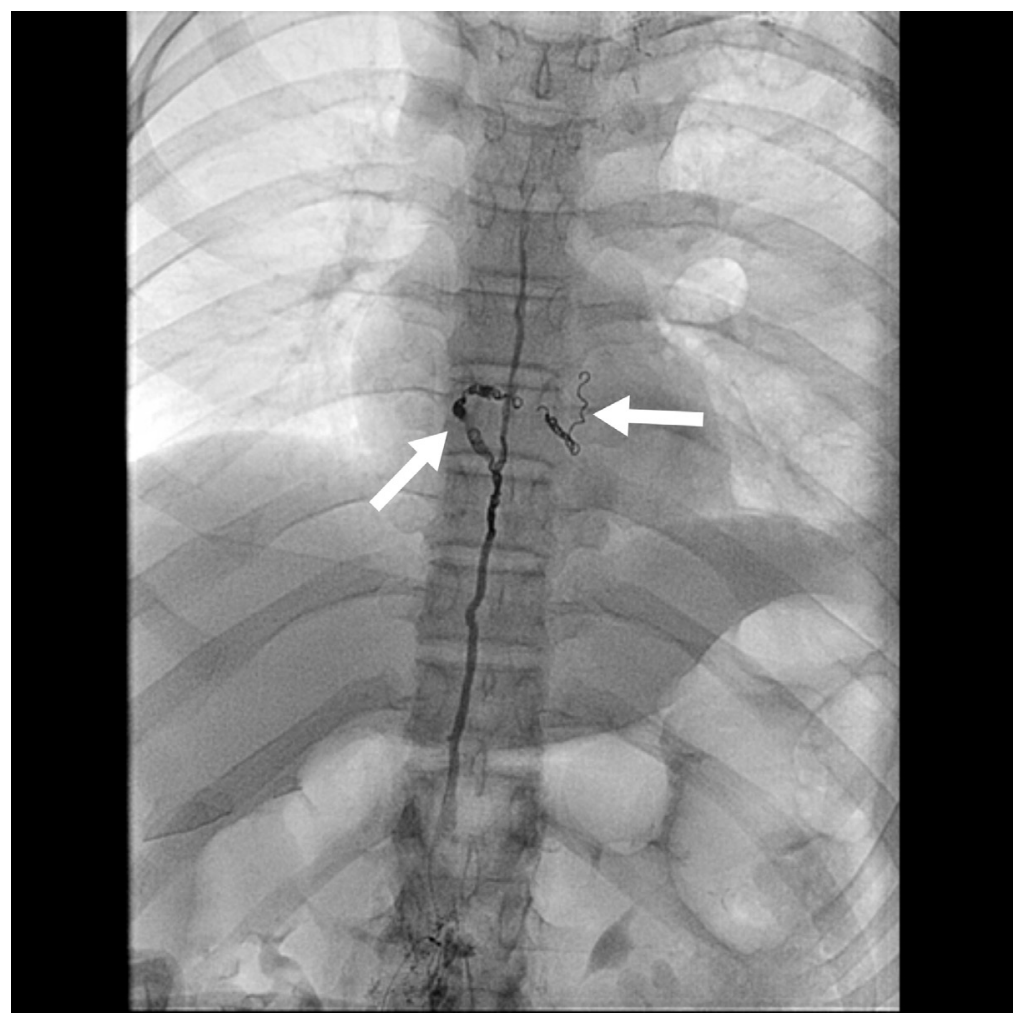

Fig. 14 Figure represents the use of microcoils (demonstrate by white arrows) for the treatment of leak through the thoracic duct. 


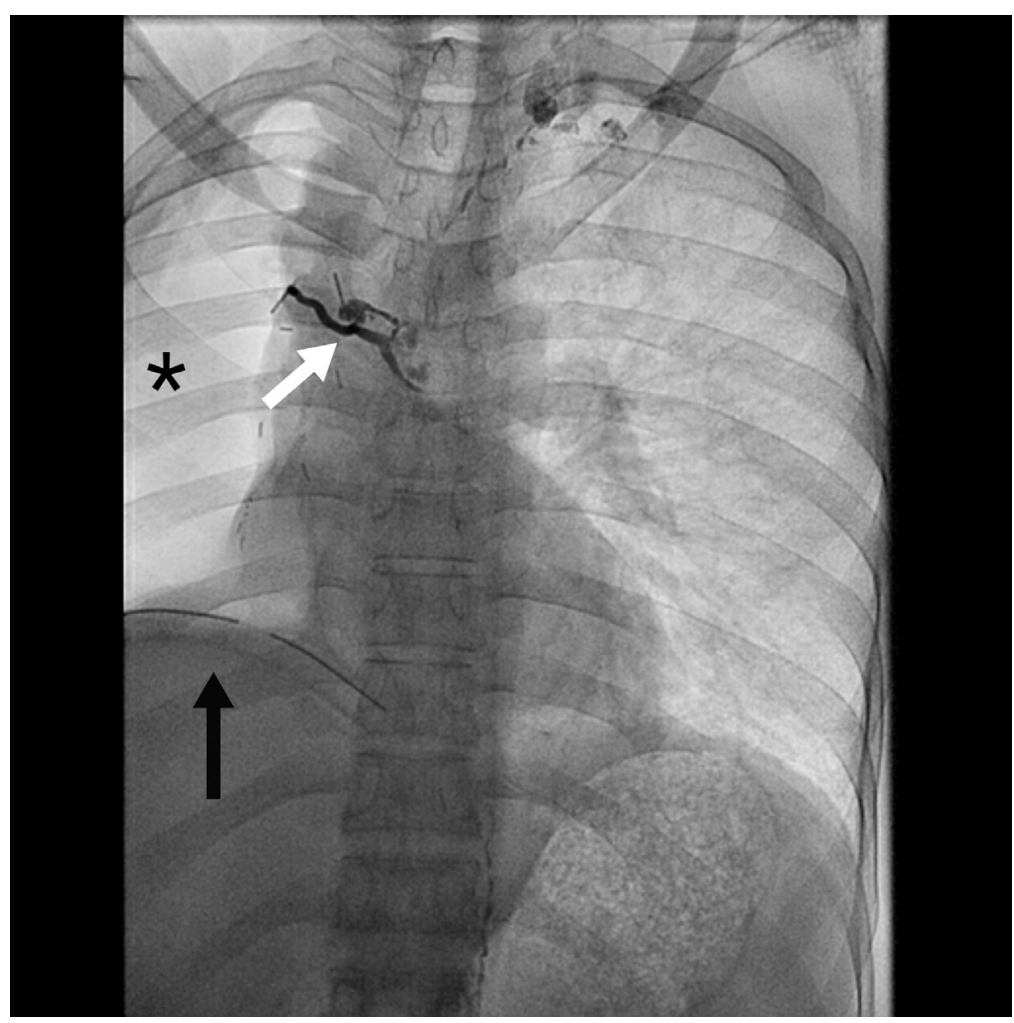

Fig. 15 Figure represents a patient who underwent right-sided pneumonectomy (marked as ${ }^{*}$ ) and later presented with persistent chylous output through drain (black arrow). On lymphangiography, leak was noted on the right side and was embolized using a glue (white arrow showing glue cast post embolization).

\section{Future of Lymphatic Intervention}

Lymphatic channels from various territories drain into the thoracic duct, thus containing metabolic products and immune factors from most regions of the body. Surgical diversion of lymph from thoracic duct has been used by many authors in the past to treat symptoms of organ rejection and improve the condition of patients with autoimmune disorders (such as rheumatoid arthritis, systemic lupus erythematosus, myasthenia gravis, and multiple sclerosis). ${ }^{28-37}$ Similarly, the drainage of lymph in patients with right heart failure and liver cirrhosis has shown significant improvement in symptoms postprocedure.

Benefits have also been suggested in acute conditions such as trauma, pancreatitis, and sepsis, where the generation of toxic metabolic products enter the circulatory system through the lymphatic network. Diversion of lymph can be helpful in these patients, preventing end-stage multiorgan failure.

Sampling and harvesting of immune cells for various immune therapies (such as chimeric antigen receptor- $\mathrm{T}$ cell therapy, commonly known as CAR-T) can also be performed and can act as a replacement for plasmapheresis in the future. ${ }^{37-40}$

\section{Conclusion}

Chyle leaks can occur anywhere in the body and are mainly due to iatrogenic causes. Lymphangiography and lymphatic intervention in the form of embolization are safe and effective in the management of these patients.

\section{Conflict of Interest}

None declared.

\section{References}

1 Natale G, Bocci G, Ribatti D. Scholars and scientists in the history of the lymphatic system. J Anat 2017;231(3):417-429

2 Margaris KN, Black RA. Modelling the lymphatic system: challenges and opportunities. J R Soc Interface 2012;9(69):601-612

3 Skandalakis JE, Skandalakis LJ, Skandalakis PN. Anatomy of the lymphatics. Surg Oncol Clin N Am 2007;16(1):1-16

4 Pinto PS, Sirlin CB, Andrade-Barreto OA, Brown MA, Mindelzun RE, Mattrey RF. Cisterna chyli at routine abdominal MR imaging: a normal anatomic structure in the retrocrural space. Radiographics 2004;24(3):809-817

5 Rosenberger A, Abrams HL. Radiology of the thoracic duct. Am J Roentgenol Radium Ther Nucl Med 1971;111(4):807-820

6 Williams PL, Bannister LH, Berry MM, Cardiovascular system. Gray's anatomy. 38th ed. New York, NY: Churchill Livingstone; 1995 1609-1611

7 Okuda I, Udagawa H, Takahashi J, Yamase H, Kohno T, Nakajima Y. Magnetic resonance-thoracic ductography: imaging aid for thoracic surgery and thoracic duct depiction based on embryological considerations. Gen Thorac Cardiovasc Surg 2009;57(12):640-646

8 Brotons ML, Bolca C, Fréchette E, Deslauriers J. Anatomy and physiology of the thoracic lymphatic system. Thorac Surg Clin 2012;22(2):139-153 
9 Kausel HW, Reeve TS, Stein AA, Alley RD, Stranahan A. Anatomic and pathologic studies of the thoracic duct. J Thorac Surg 1957;34(5):631-641

10 Phang K, Bowman M, Phillips A, Windsor J. Review of thoracic duct anatomical variations and clinical implications. Clin Anat 2014;27(4):637-644

11 Pupulim LF, Vilgrain V, Ronot M, Becker CD, Breguet R, Terraz S. Hepatic lymphatics: anatomy and related diseases. Abdom Imaging 2015;40(6):1997-2011

12 Ohtani O, Ohtani Y. Lymph circulation in the liver. Anat Rec (Hoboken) 2008;291(6):643-652

13 Miller MJ, McDole JR, Newberry RD. Microanatomy of the intestinal lymphatic system. Ann NY Acad Sci 2010;1207(1, Suppl 1): E21-E28

14 Guermazi A, Brice P, Hennequin C, Sarfati E. Lymphography: an old technique retains its usefulness. Radiographics 2003;23(6):1541-1558, discussion 1559-1560

15 Chavhan GB, Amaral JG, Temple M, Itkin M. MR lymphangiography in children: technique and potential applications. Radiographics 2017;37(6):1775-1790

16 Cellina M, Oliva G, Menozzi A, Soresina M, Martinenghi C, Gibelli D. Non-contrast magnetic resonance lymphangiography: an emerging technique for the study of lymphedema. Clin Imaging 2019;53:126-133

17 Krishnamurthy R, Hernandez A, Kavuk S, Annam A, Pimpalwar S. Imaging the central conducting lymphatics: initial experience with dynamic MR lymphangiography. Radiology 2015;274(3):871-878

18 Lass P, Tomczak H, Nyka W, Studniarek M. Diagnostic imaging of lymphoedema- The role of lymphoscintigraphy. Promlemy Medycyny Nuklearnej. 2004;18(36):169-176

19 Munn LL, Padera TP. Imaging the lymphatic system. Microvasc Res 2014;96:55-63

20 Doerr CH, Allen MS, Nichols FC III, Ryu JH. Etiology of chylothorax in 203 patients. Mayo Clin Proc 2005;80(7):867-870

21 Cerfolio RJ, Allen MS, Deschamps C, Trastek VF, Pairolero PC. Postoperative chylothorax. J Thorac Cardiovasc Surg 1996; 112(5):1361-1365, discussion 1365-1366

22 Dougenis D, Walker WS, Cameron EW, Walbaum PR. Management of chylothorax complicating extensive esophageal resection. Surg Gynecol Obstet 1992;174(6):501-506

23 Agrawal V, Doelken P, Sahn SA. Pleural fluid analysis in chylous pleural effusion. Chest 2008;133(6):1436-1441

24 Nair SK, Petko M, Hayward MP. Aetiology and management of chylothorax in adults. Eur J Cardiothorac Surg 2007; 32(2):362-369

25 Marts BC, Naunheim KS, Fiore AC, Pennington DG. Conservative versus surgical management of chylothorax. Am J Surg 1992;164(5):532-534, discussion 534-535
26 Inoue M, Nakatsuka S, Yashiro H, et al. Lymphatic intervention for various types of lymphorrhea: access and treatment. Radiographics 2016;36(7):2199-2211

27 Hur S, Shin JH, Lee IJ, et al. Early experience in the management of postoperative lymphatic leakage using lipiodol lymphangiography and adjunctive glue embolization. J Vasc Interv Radiol 2016;27(8):1177-1186.e1

28 Fish JC, Sarles HE, Remmers A Jr, Townsend CM Jr, Bell JD, Flye MW. Renal transplantation after thoracic duct drainage. Ann Surg 1981;193(6):752-756

29 Machleder HI, Paulus H. Clinical and immunological alterations observed in patients undergoing long-term thoracic duct drainage. Surgery 1978;84(1):157-165

30 Wegelius O, Laine V, Lindström B, Klockars M. Fistula of the thoracic duct as immunosuppressive treatment in rheumatoid arthritis. Acta Med Scand 1970;187(6):539-544

31 Bonomini V, Mioli V, Albertazzi A, Vangelista A. Immunosuppressive drugs and lymphatic depletion by thoracic duct fistula in adult progressive glomerulonephritis. Nephron 1970;7(5):389-399

32 Ravnskov U, Dahlba"ck O, Messeter L. Treatment of glomerulonephritis with drainage of the thoracic duct and plasmapheresis. Acta Med Scand 1977;202(6):489-494

33 Nyman KE, Bangert R, Machleder H, Paulus HE. Thoracic duct drainage in SLE with cutaneous vasculitis. A case report. Arthritis Rheum 1977;20(5):1129-1134

34 Bergström K, Franksson C, Matell G, et al. Drainage of thoracic duct lymph in twelve patients with myasthenia gravis. Eur Neurol 1975;13(1):19-30

35 Ring J, Seifert J, Lob G, et al. Intensive immunosuppression in the treatment of multiple sclerosis. Lancet 1974;2(7889) :1093-1096

36 Sarles HE, Remmers AR Jr, Fish JC, et al. Depletion of lymphocytes for the protection of renal allografts. Arch Intern Med 1970;125(3):443-450

37 Fanous MYZ, Phillips AJ, Windsor JA. Mesenteric lymph: the bridge to future management of critical illness. JOP 2007;8(4):374-399

38 Brzek V, Bartos V. Therapeutic effect of the prolonged thoracic duct lymph fistula in patients with acute pancreatitis. Digestion 1969;2(1):43-50

39 Witte MH, Horowitz L, Dumont AE. Use of thoracic-duct cannulation in the diagnosis of tuberculous enteritis. N Engl J Med 1963;268:1125-1126

40 Lim WA, June $\mathrm{CH}$. The principles of engineering immune cells to treat cancer. Cell 2017;168(4):724-740 